\title{
Métodos geofísicos aplicados ao estudo do assoreamento da unidade hidrográfica do Torto, no Lago Paranoá, Brasília/DF.
}

Kamylla de Lima Alves* (limaalves.k@gmail.com - Graduanda em Geofísica do IG/UnB)

Aline Isabel de Pádua (aline.geofisica@gmail.com - Graduanda em Geofísica do IG/UnB)

Marco lanniruberto (ianniruberto@unb.br - Docente do IG/Unb)

Welitom Borges (welitom@unb.br - Docente do IG/Unb)

\section{Copyright 2016, SBGf - Sociedade Brasileira de Geofísica}

Este texto foi preparado para a apresentação no VII Simpósio Brasileiro de Geofísica. Ouro Preto, 25 a 27 de outubro de 2016. Seu conteúdo foi revisado pelo Comitê Técnico do VII SimBGf, mas não necessariamente representa a opinião da SBGf ou de seus associados. É proibida a reprodução total ou parcial deste material para propósitos comerciais sem prévia autorização da SBGf.

\section{Resumo}

The siltation in reservoir is a recurring problem today as a consequence of increased soil erosion due to land use changes by human activities. Quantify sediment discharge is not easy because it involves several issues, such as monitoring tributaries and direct runoff from the margins. However, the use of geophysical methods may serve as auxiliary tools to determine geometry and volume of deposited sediments, as well as its temporal variability. In Ribeirão Torto, which flows into the Paranoa Lake, resistivity method and bathymetry proved extremely effective in the qualification and quantification of this phenomenon. This study shows that the contribution of sediment of the river basin, adversely affecting the Paranoa Lake reducing the useful volume.

\section{Introdução}

A problemática dos sistemas aquáticos das bacias do Rio Paranoá existe em decorrência da ocupação intensiva, do diversificado padrão de uso do solo e da falta de planejamento do processo de urbanização. Esta degradação vem acarretando a perda de cobertura vegetal nativa, o aumento de processos erosivos, alterações na qualidade da água e o assoreamento dos corpos hídricos (Menezes, 2010).
Em regiões submersas, a utilização de método geofísicos, principalmente métodos que fazem uso de ondas acústicas, fornecem uma visa mais vasta e contínua da superfície e subsuperfície da área investigada. Ademais, tratam-se de métodos não invasivos e que não proporcionam prejuízos ambientais. A aplicação destes métodos na manutenção e estudo de reservatórios é de grande relevância e tem se tornado fundamental para análise qualitativa e quantitativa no processamento de assoreamento de reservatórios. (SOUZA, 2006).

De acordo com (MAIA et al, 2005) Os sedimentos no Lago Paranoá são derivados de materiais das margens, tributários, atmosféricos e residuais (referente material existente antes do preenchimento do lago).

A Bacia do Lago Paranoá apresenta uma área de aproximadamente $1034,07 \mathrm{~km}^{2}$ e está inserida na parte central do Distrito Federal. O lago foi formado no ano de 1959 represando águas dos ribeirões Riacho Fundo, Gama, Torto e Bananal. Exibe uma cota populacional significativa, tendo em vista que nessa Bacia estão situadas diversas regiões administrativas de Brasília (FONSECA, 2001). Neste estudo, daremos foco apenas à unidade hidrográfica do Torto (Figura 1).

O Ribeirão Torto desemboca diretamente no Lago Paranoá com vazão média de $2,89 \mathrm{~m} 3 / \mathrm{s}$. O curso principal possui cerca de $20 \mathrm{~km}$ de comprimento e sua área de drenagem possui aproximadamente $249,76 \mathrm{~km} 2$. O seu regime hídrico não é mais natural, devido a
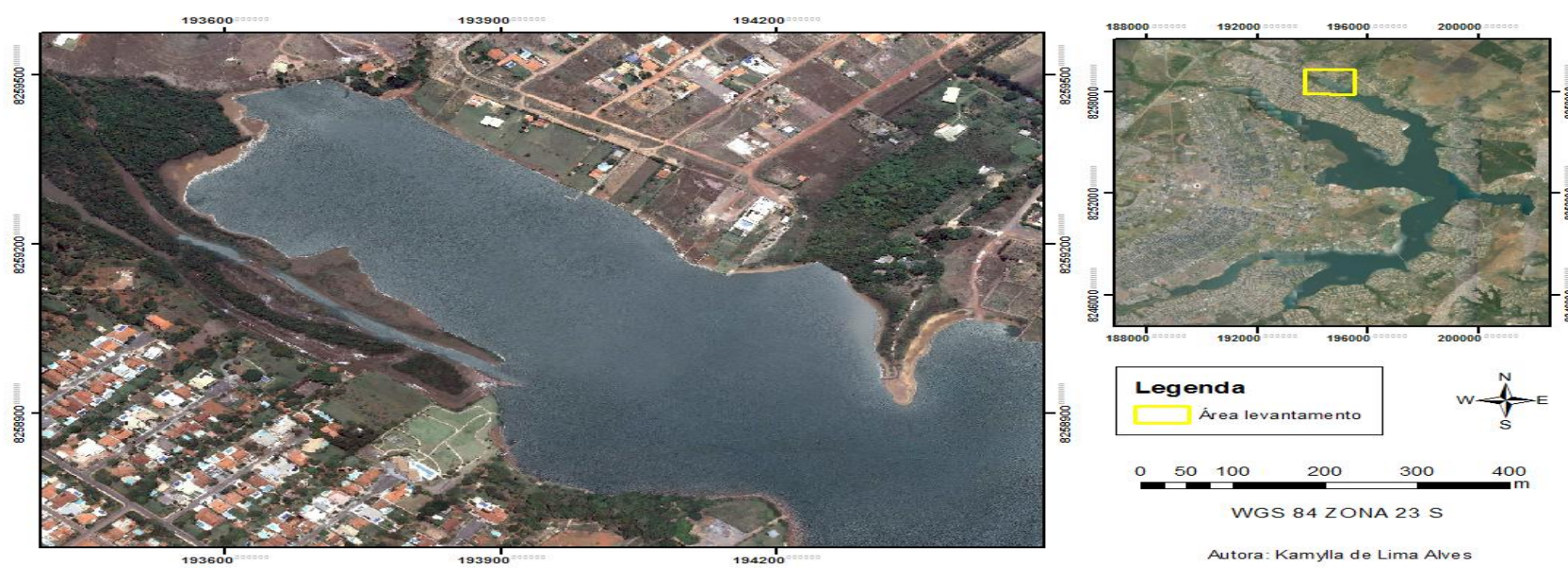

Figura 1: Mapa de localização da área do levantamento. 
construção das barragens de Santa Maria e Torto.

Este trabalho tem como objetivo verificar a eficácia dos métodos geofísicos no processo de assoreamento no braço do Rio Torto no Lago Paranoá, realizar uma análise temporal comparando com estudos anteriores, bem como analisar de maneira qualitativa e qualitativa a pluma de sedimentação.

\section{Metodologia/ Problema Investigado}

(MACHADO, 2008) Sugere em seu trabalho métodos geofísicos de alta resolução junto aos métodos convencionais para a medição de camadas sedimentares, e obtenção de conhecimento sobre o volume real de sedimento e volume de aporte do reservatório. Assim, é possível um acompanhamento do volume útil do reservatório e análise do processo de assoreamento.

\section{Batimetria}

$\mathrm{Na}$ aquisição de dados batimétricos, utilizou-se o Ecobatímetro hidrográfico ODOM Echotrac CVM, dupla frequência (33 e $200 \mathrm{kHz}$ ), acoplado à uma antena GPS e ao sistema de navegação no software HYPACK 2010. As linhas de aquisição e as linhas de controle foram planejadas numa malha regular com um espaçamento de 20 metros.

O processamento de dados ocorreu no software HYPACK 2010. A rotina de processamento consistiu em: primeiramente realizar o controle de qualidade com a retirada dos picos 'spikes'. Após a retirada, aplicou-se a redução ao datum vertical de 1000 metros sobre o nível do mar, segundo a Resolução ADASA no 06/2015 para o Lago Paranoá. A interpolação foi realizada com o software Surfer $8 \mathrm{com}$ a técnica de interpolação Kriging.

\section{Método Elétrico}

Para o levantamento de resistividade, foram planejadas sete linhas longitudinais com espaçamento de 50 metros e outras sete linhas transversais espaçadas a 150 metros. Foi utilizado o Syscal Pro da Iris Instrument conectado ao Sysmar e acoplado à batimetria. A aquisição é feita de maneira contínua, de modo que os cabos são arrastados na superfície da água afim de obter a seção com variações de resistividade elétrica dos materiais de subsuperfície. $\mathrm{O}$ arranjo adotado foi Wenner com espaçamento entre os eletrodos de 2,5 metros.

No processamento de dados elétricos utilizou-se o software Prosys II para retirada dos spikes. Em seguida, os dados foram exportados para o software de inversão Res2dinv.

\section{Taxa de sedimentação}

A espessura da camada de sedimentos assoreados foi calculada através da diferença dos mapas batimétricos de 2009 e 2016. A taxa de sedimentação foi então obtida por meio da divisão da espessura pelo número de anos corridos -6 anos.

\section{Resultados}

\section{Batimetria}

A interpolações dos dados batimétricos é apresentada na figura seguinte. O grid foi recortado nas bordas, próximo aos dados coletados, afim de minimizar o efeito de borda e evitar o falseamento dos dados.

A imagem demonstra os valores de profundidade no braço do Torto. É notório que no deságue dos efluentes há um acúmulo de sedimentos, devido á diminuição da capacidade de transporte do fluxo, como evidenciado na (Figura 2- b), pela pluma de deposição situada na foz do corrego e com profundidades inferiores a $1 \mathrm{~m}$.

Para uma melhor análise e comparação dos dados, foi feito um grid com dados batimétricos adquiridos em uma campanha de 2009 (Figura 2-a), coletados com a mesma metodologia. Desta forma, é possível verificar que há uma tendência do aumento da área assoreada e espalhamento da pluma de sedimentação.

Com o grid da diferença entre os dados batimétrico de 2016 e 2009 (Figura 3), é possível visualizar a pluma de sedimentos se formando no deságue do Ribeirão Torto. A variação máxima de profundidade no período analisado é de 1,7 metros.

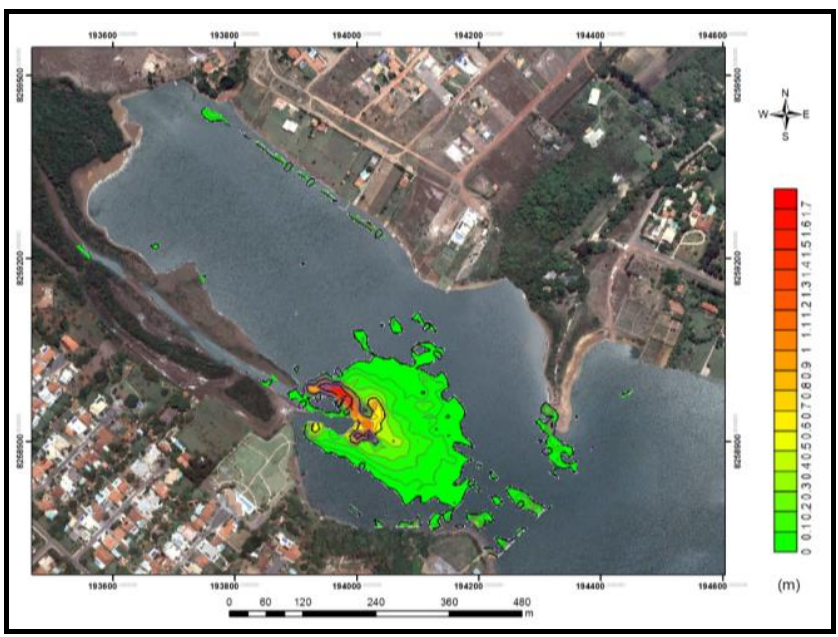

Figura 3: Grid da diferença de valores entre 2016 e 2009.

O grid da taxa de sedimentação (Figura 4) foi obtido através do grid da diferença 2016 - 2009 dividido pelo número de anos decorridos (sete). Desta maneira foi possível obter de maneira qualitativa o quanto essa pluma cresce a cada ano, atingindo um máximo de $20 \mathrm{~cm}$ por ano. 


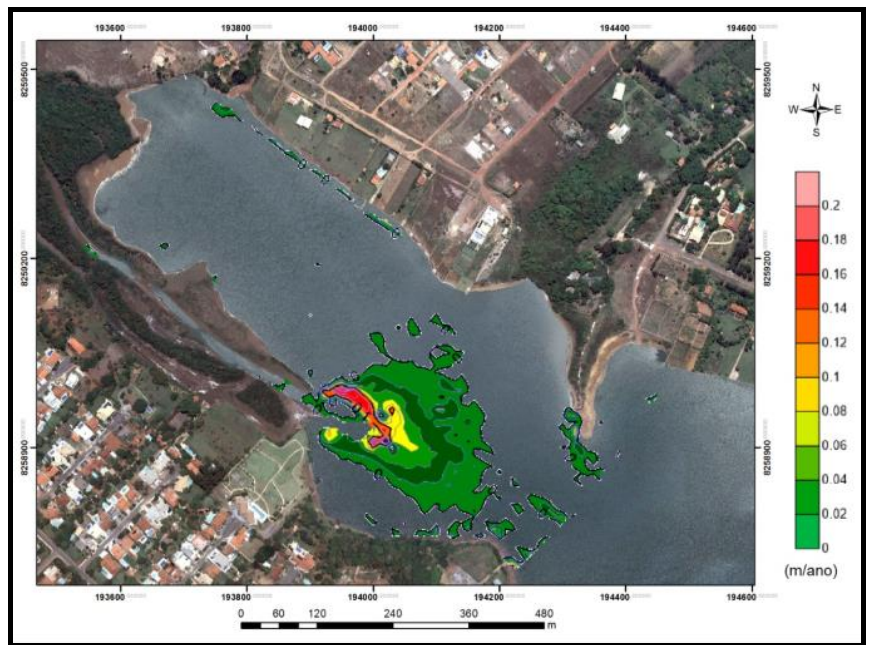

Figura 2: Taxa de sedimentação por ano.

\section{Métodos Elétricos}

A linha localizada perpendicular ao fluxo do ribeirão (Figura 4), foi selecionada afim de obter uma melhor visualização da pluma de sedimentos.

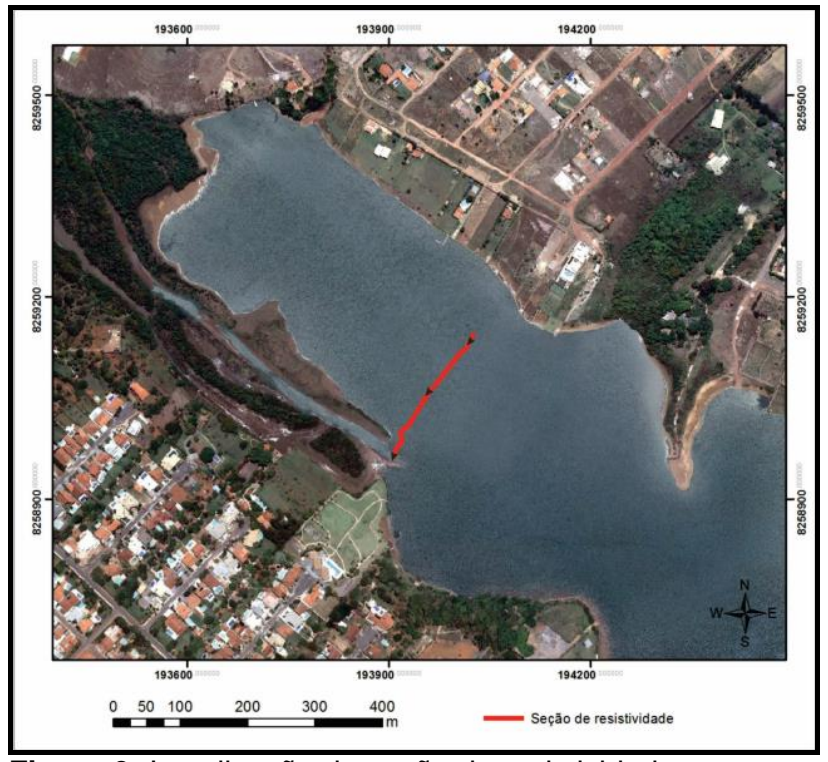

Figura 3: Localização da seção de resistividade.

È possível visualizar a lâmina d'água acima da topografia, em sequência as porções dos sedimentos mais resistivos (rosa), arenoso, que pode ser considerado um material recente, proveniente da construção da rodovia. Ao sudoeste da linha, é notório uma pluma de sedimentação (laranja), com espessura de 1,9 metros aproximadamente, de alta condutividade, que caracteriza material argiloso com presença de matéria orgânica. Nota-se também a presença deste mesmo material ao centro da seção, que pode ser interpretado como o paleocanal e seus meandros, visto que no mapa batimétrico é possível observar essa estrutura. Em seguida, observa-se um material de alta resistividade(cinza), que pode ser interpretado como latossolo - solo existente antes do preenchimento do lago.

\section{Discussão e Conclusões}

Os resultados aprovam a eficácia da batimetria e mostra que o método por ser de extrema relevância. Quando aplicados com certa frequência, podem fornecer informações qualitativas, como carga de sedimentos, espessura da pluma e locais propícios ao assoreamento. De tal modo, é viável a realização de monitoramento para planos de gestão de recursos hídricos.

Pretende-se realizar mais uma campanha de aquisições de eletrorresistividade na região, para elaboração do 3D afim de ter uma delimitação da calha de sedimentos na desembocadura do lago. Desta forma, será possível fazer uma análise quantitativa mais completa e integrada com a batimetria para uma melhor determinação da pluma.

\section{Agradecimentos}

À Diretoria de Fomento à Iniciação Científica da Universidade de Brasília pela oportunidade de desenvolver a Pesquisa de PIBIC.

Ao Laboratório de Geofísica Aplicada (LGA) da UnB pela disponibilização dos equipamentos.

\section{Referências}

FONSECA, F. O. (SECRETARIA DO M. A. E R. H. Olhares sobre o Lago Paranoá. 1 edição ed. Brasília/DF: [s.n.].

MACHADO, R. Aplicação do método eletrorresistivo em ambiente aquático para o mapeamento de subfundo do Rio São Francisco. [s.l.] Universidade de São Paulo, 2008.

MAIA, P. D. et al. Estudo mineralógico dos sedimentos de fundo do Lago Paranoá, Distrito Federal. Revista Brasileira de Geociências, v. 35, n. 4, p. 535-541, 2005.

MENEZES, P. H. B. J. 2010. Avaliação do efeito das ações antrópicas no processo de escoamento superficial e assoreamento na Bacia do Lago Paranoá. Dissertação de Mestrado - Universidade de Brasília - UnB, BrasíliaDF. 133p.

SOUZA, L. A. P. Revisão crítica da aplicabilidade dos métodos geofísicos na investigação de áreas submersas rasas. [s.l.] Universidade de São Paulo, 2006.

TELFORD, W. M.; GELDART, L. P.; SHERIFF, R. E. Applied Geophysics. Second Edi ed. [s.I.] Cambridge University, 1990. 


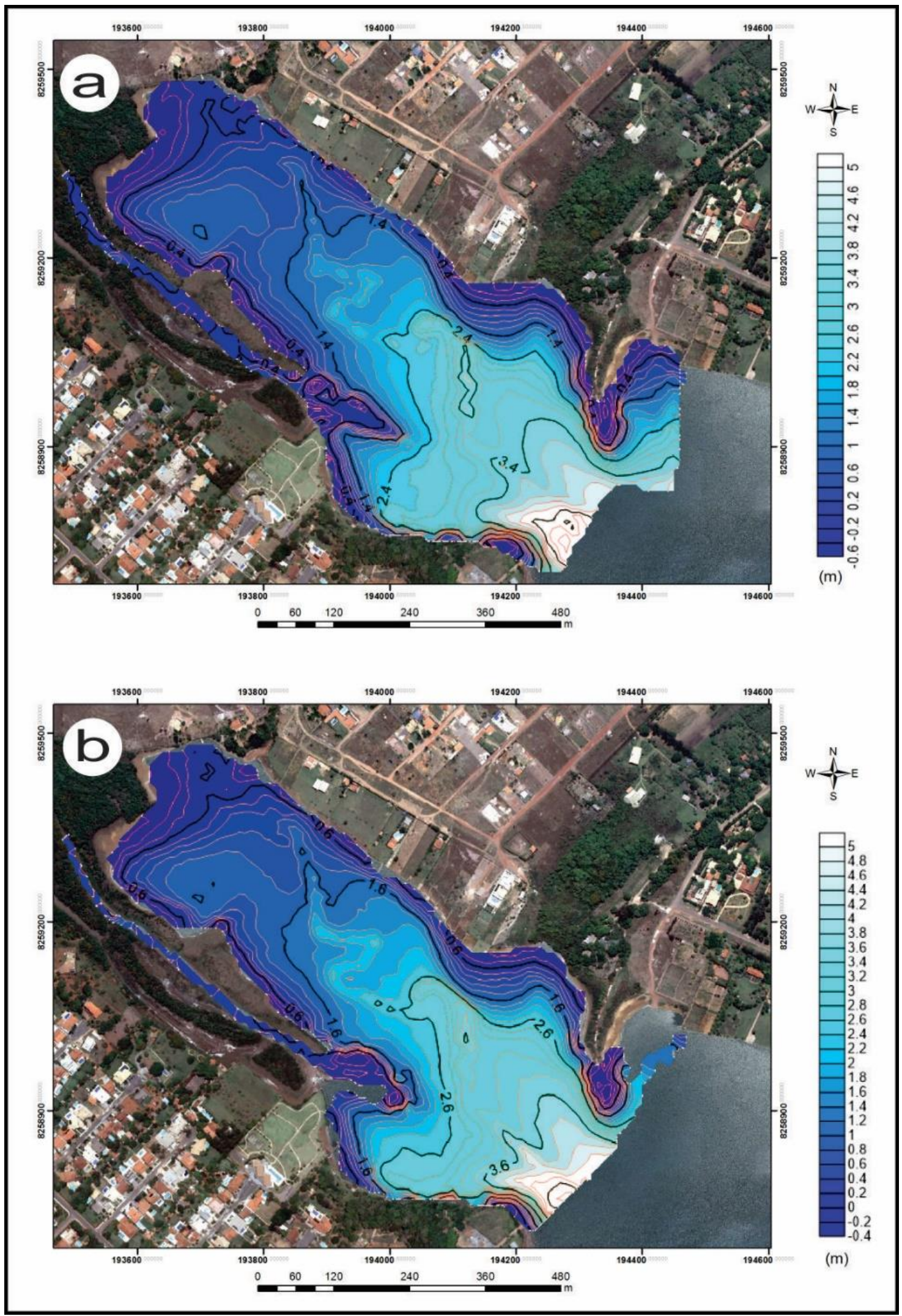

Figura 2: Mapas batimétricos a) Batimetria realizada em 2009 b) Batimetria realizada em 2016. 


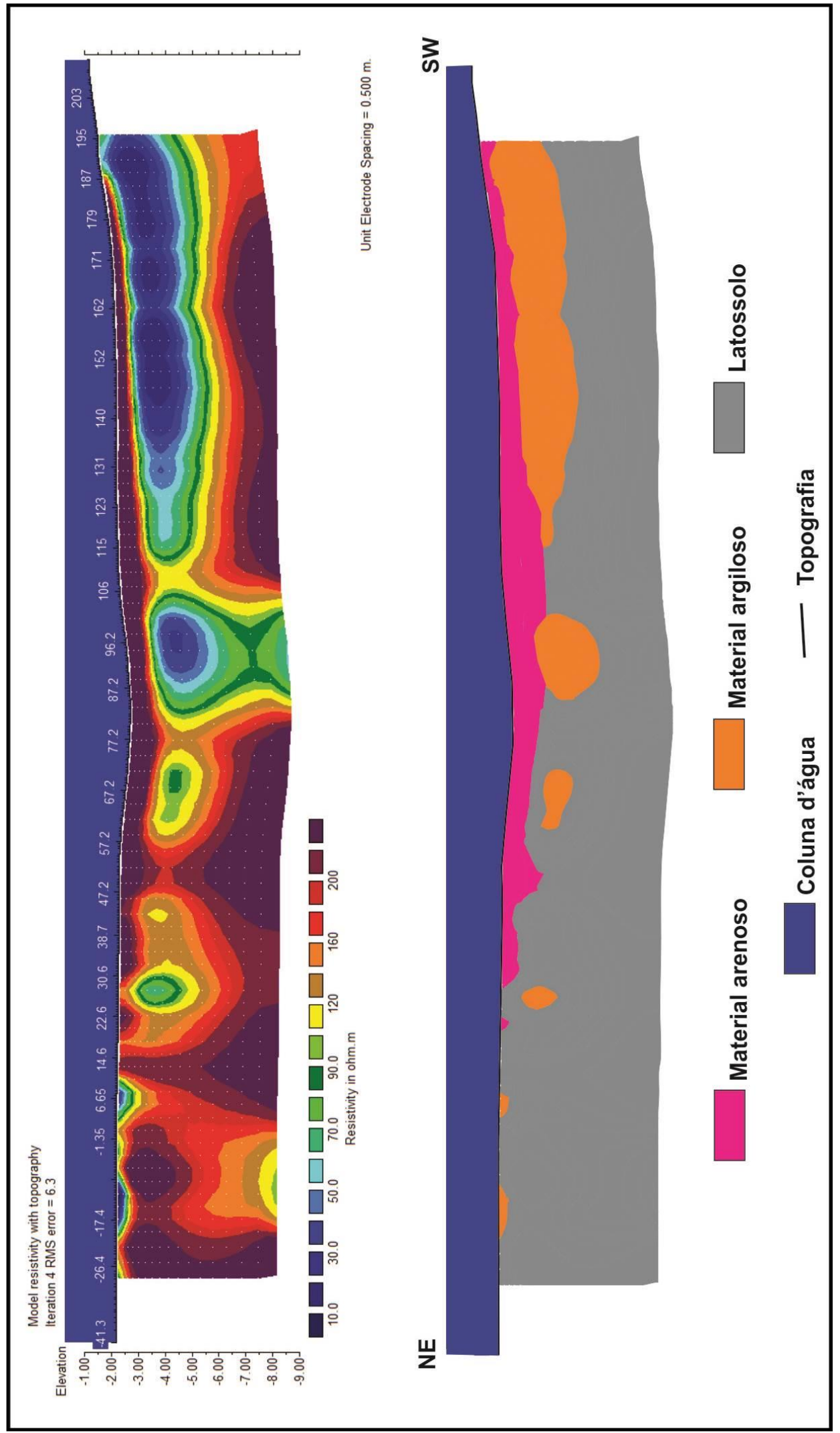

Figura 4: Seção de resistividade com interpretação. 